\title{
Espacio teatral en la encrucijada tecnovivial: implicancias territoriales
}

\author{
(4) Mario Leandro Arce De Piero \\ ICSOH-CONICET-UNAS, Argentina \\ leandroarcedepiero@gmail.com
}

Fecha de recepción: 14/08/2021. Fecha de aceptación: 28/09/2021

\begin{abstract}
Resumen
El empleo de artefactos tecnológicos y de la red de internet han sido los recursos más explotados por los artistas de todo el país y del mundo para sostener su actividad en estos últimos tiempos. Ahora bien, ¿cómo impacta esta emergencia en la perspectiva de los estudios teatrales? El teatro tecnovivial no solo nos plantea un programa poético específico, explícito y decidido que buscó dar respuesta a esta coyuntura y resolver el particular desafío del empleo de aparatos para la producción de acontecimientos teatrales, sino que también nos lleva a reconsiderar la relación entre cuerpo, espacio y tiempo en la construcción de territorios posibles inéditos. El teatro tecnovivial nos hace repensar el rol que cumple el espacio en la producción del acontecimiento teatral. A partir del análisis de tres casos, revisamos el funcionamiento del espacio en el teatro tecnovivial, la problemática que involucra a quienes buscan legitimar esta práctica y, finalmente, las implicancias territoriales sobre la configuración del campo teatral.
\end{abstract}

Palabras claves: territorialidad, espacio teatral, convivio, tecnovivio, cartografía teatral

\section{Theatrical Space at the Technovivial Crossroads: Territorial Implications}

\begin{abstract}
Technological devices and the Internet have been the most exploited resources by artists from all over the country and the world to sustain their activity in recent years of emergency. Now, how does this emergency impact the perspective of theater studies? Technovivial theater not only presents us with a specific, explicit and decisive poetic program that sought to respond to this situation and solve the particular challenge of using devices for the production of theatrical events, but also leads us to reconsider the relationship between the body, space and time in the construction of possible new, unexplored territories. Technovivial theater thus makes us rethink the role that space plays in the production of the theatrical event. Based on the analysis
\end{abstract}


of three cases, we review how space works in technovivial theater, the problems faced by those who seek to legitimize this practice and, finally, the territorial implications on the theatrical field's configuration.

Keywords: territoriality, theatrical space, conviviality, technovivial, theatrical cartography

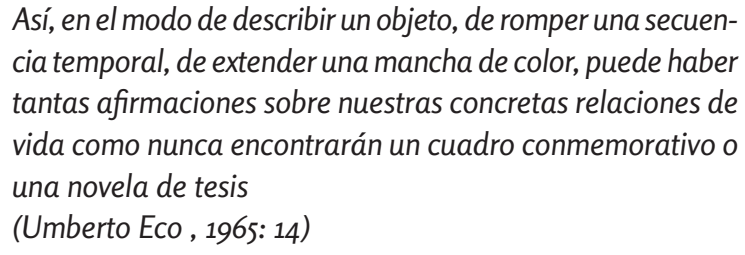

\section{Introducción}

Sabemos que el 2020 ha sido un año difícil para los hacedores teatrales. El empleo de artefactos tecnológicos y de la red de internet han sido los recursos más explotados por los artistas de todo el país y del mundo para sostener su actividad. Ahora bien, ¿cómo impacta esta emergencia en la perspectiva de los estudios teatrales? El teatro tecnovivial no solo nos plantea un programa poético específico, explícito y decidido que buscó dar respuesta a esta coyuntura y resolver el particular desafío del empleo de aparatos para la producción de acontecimientos teatrales, sino que también nos lleva a reconsiderar la relación entre cuerpo, espacio y tiempo en la construcción de territorios posibles inéditos. Por lo tanto, abre una perspectiva para indagar entre los vínculos entre los postulados de la filosofía del teatro y la elaboración de cartografías teatrales.

Nos proponemos pensar el rol del espacio en el teatro convivial y en el teatro tecnovivial a la luz de algunas obras que fueron puestas en escena a lo largo del $2020 \mathrm{y}$, con esto, dilucidar las posibilidades y límites de la producción del acontecimiento teatral mediado por la virtualidad. Entendiendo que el convivio solo es posible por la presencia en un espacio contiguo de artistas, técnicos y espectadores, nos preguntamos por el modo en que la discontinuidad de los cuerpos impacta en el acontecimiento. Todas las obras analizadas tienen en común el haber sido producidas empleando aparatos tecnológicos y recepcionadas en idéntica coyuntura geográfica, aunque reconocemos que cada vez la territorialidad producida haya tenido sus propias características.

Queda claro que el teatro tecnovivial nos lleva a reconsiderar el rol que cumple el espacio en la producción del acontecimiento teatral. El devenir interpretativo que proponemos no busca agotar la discusión ni la producción de experiencias en torno a la obra, sino más bien enmarcarla; por ello mismo, tampoco es un ejercicio de crítica teatral que tenga como finalidad establecer el valor de las obras, sino que buscamos considerar algunos criterios posibles para su realización. Por esto nos interesa destacar algunos recursos del teatro tecnovivial que nos sirven para delinear los alcances de esta noción. De esta forma buscamos contribuir a la comprensión de este fenómeno en auge.

\section{Emergencia sanitaria, búsquedas estéticas en un mundo en crisis y pregunta ontológica}

Es interesante constatar que en el último año el cierre preventivo de teatros para evitar la propagación de Covid-19 ha sido una estrategia global que, en el contexto argentino, ha exigido la reformulación masiva de los modos de hacer, comunicar y 
presenciar el teatro. Han proliferado un conjunto de prácticas que han tenido como objetivo resistir a la coyuntura social y que desestabilizan lo que entendemos por el teatro y la relación entre los cuerpos en el espacio-tiempo.

Hoy, el teatro tecnovivial se encuentra en una situación inédita. Mientras que la posible investigación artística en este ámbito anteriormente estuvo supeditada a exploraciones particulares que responden a las exigencias del contexto solo de forma parcial, en términos de que la existencia de los recursos tecnológicos necesarios para estas producciones no provocó apropiaciones creativas masivas, a lo largo del 2020 fue el producto de exigencias contextuales muy particulares lo que ha llevado a una investigación colectiva, de gran alcance y con la emergencia de escalas territoriales insospechadas.

En la definición pragmática del teatro, Jorge Dubatti señala que "el teatro es la fundación de una peculiar zona de la experiencia y subjetividad en la que intervienen convivio-poíesis-expectación" (2010: 33), entonces, el presupuesto pragmático que sostiene esta definición del teatro es que existe un espacio y tiempo compartidos por actores, técnicos y espectadores y que permite la producción del hecho artístico. La filosofía del teatro ha definido al teatro como acontecimiento cuya poíesis es corporal y en la que intervienen la presencia de, por lo menos, un actor que se ocupa de la poiesis productiva y de un espectador cuya función es la realización de la poiesis receptiva. De este modo, "El teatro es espacio y tiempo compartidos en una misma zona de afectación, zona única que se crea una sola vez y de forma diferente en cada función." (Dubatti, J., 2015: 46).

En este marco, espacio, tiempo y cuerpo son rasgos que permiten identificar ontológicamente un acontecimiento propiamente teatral de otras formas culturales no teatrales, como el cine o la televisión, donde habría una autonomía de los momentos de producción y recepción, o las grabaciones de obras teatrales, que funcionan como un registro o que habilitan la reproducción mecánica de la huella del acontecimiento y no del hecho en sí. Afortunadamente, la proliferación de prácticas tecnoviviales y, específicamente, la exploración de las posibilidades y límites del teatro mediado por la pantalla, hizo de la pregunta ontológica objeto de renovadas y múltiples discusiones.

Así lo manifiesta Verónica Pérez Luna en un posteo en su perfil personal en Facebook. Nos interesa citar extensamente porque, además de constatar la urgencia ontológica por la definición del teatro, sitúa esta búsqueda existencial en relación con una modalidad de práctica artística que se funda, justamente, en la experimentación y el cuestionamiento de la práctica:

Leyendo varios posteos en estos tiempos sobre lo que es y no es teatro, me viene a la cabeza todas las veces que a Manojo de Calles le han dicho que lo que hace no es teatro. Recuerdo una vez en el 2010 cuando actúe en "Cuestión de principios" junto a Juan Tríbulo bajo la dirección de Leonardo Goloboff, permitiéndome probar otra poética muy diferente a la poética que me identifica, nuestra querida Rosita Ávila al finalizar la obra me grita en medio de los aplausos:

- Por fin te veo haciendo teatro chinita!!!

Yo ya tenía 44 años y llevaba unos 25 años haciendo teatro o lo que sea como se llame. Yo me reí y la abracé con cariño y reconocimiento por todo su aporte al teatro tucumano.

Sí es verdad que Manojo de Calles ya parece una teatralidad reconocida en el medio pero de ninguna manera somos palabra "autorizada", muy por el contrario constantemente se cuestiona o se pone en disvalor el teatro que nos nace (...) (Verónica Pérez Luna, 3-09-2020) 
Posteriormente a este posteo, el Grupo "Un colectivo con un manojo de artistas que dan otra vuelta al teatro" (CMT) estrena 5 Pesos (versión libre de El Público de F. García Lorca), cuya dirección colectiva estuvo a cargo de Verónica Pérez Luna, Fabiola Vilte y Diego López..

El estreno se llevó a cabo el sábado 21 de noviembre, vía Zoom. Además de señalar la proveniencia interprovincial de los integrantes del Grupo, el alcance del público reunido en la sala no estaba supeditado al movimiento físico del espectador, por lo cual se podía prever el encuentro de espectadores de múltiples geografías en la misma sala. La propuesta fue realizada por tres colectivos del NOA: Manojo de Calle de Tucumán, La Otra Vuelta de Salta, El Colectivo Teatro de Jujuy, que comparten una misma mirada sobre el teatro, sobre lo grupal y lo colectivo.

La puesta en escena se organiza en el espacio de la sala de Zoom. Actores, técnicos y espectadores ocupan la misma plataforma. Al inicio de la sesión, una acomodadora (función y personaje) solicita al público que apague las cámaras mientras dura el espectáculo. Al final de la puesta se dispone un espacio-tiempo para que todos los participantes se saluden, activando sus cámaras y micrófonos en la sala. Este encuentro entre espectador y actor aparece como punto problemático en tanto la posibilidad o no de que se concrete depende la posibilidad de definir el acontecimiento como un hecho teatral. De acuerdo con los integrantes del grupo, efectivamente, toda experimentación y cuestionamiento debe estar subordinado a la realización de este encuentro:

(...) pero seguimos buscando la manera de llegar al otre, de producir el encuentro con el otre porque sin duda todes deseamos ser queridos o mirados con "amor"; pero obviamente sin traicionar nuestros pensamientos estéticos e ideológicos sobre el teatro porque ahí está el valor de cada forma artística, de cada acto creador en su propia búsqueda y cada une aporta lo suyo a esta maravillosa arte (...) (Verónica Pérez Luna, 03-09-2020)

Estos productos elaborados con la intervención de pantallas, celulares, plataformas como Whatsapp, Telegram o Zoom, ¿pueden ser considerados teatro? ¿Clausuran irremediablemente (e invariablemente) la posibilidad del convivio? y, ya sea la respuesta afirmativa o negativa, ¿tienen algo para enseñarnos sobre las prácticas teatrales pretéritas, contemporáneas y futuras? ¿Qué tiene el tecnovivio para ofrecer al teatro o es posible el teatro tecnovivial? La respuesta a estos interrogantes dependen de los territorios en los que las obras se inscriben e involucra a los hacedores, espectadores, críticos, teóricos en sus roles específicos, visibilizando una trama compleja de legitimación y valoración de las producciones particulares. Esto no deja de ser problemático en tanto una misma producción puede participar de territorios diversos, producto de la multiterritorialidad característica de las sociedades contemporáneas (cfr. Haesbaert, 2011)

\section{Producción de valor y legitimidad de las prácticas teatrales tecnoviviales: apuntes sobre el tiempo presente}

Como lo señala en su anécdota Verónica Pérez Luna, el reconocimiento de la teatralidad de una práctica es correlativa al valor que se le atribuye. En este sentido, consideramos que el valor no es inherente de la práctica, sino del lugar que ésta ocupa en la trama social. Los debates en torno a la definición del teatro vienen a revelar luchas por la acumulación de un capital cultural específico mediante la cual no todos ocupan el mismo lugar en el campo y, lo que es más importante, se produce una desigualdad en la distribución del valor simbólico y del capital cultural hacia adentro del circuito restringido de la producción con efectos en la producción de valor (Bourdieu, 2010). 
Por eso proponemos revisar las diferencias ontológicas entre el teatro tecnovivial y teatro convivial que nos permiten considerarlos, en sus diferencias, como teatro, es decir, como artefactos del mismo dispositivo cultural. Ni la poiesis corporal ni la expectación están en discusión en función de que en ambas formas las poiesis productiva y receptiva se dan en relación con los cuerpos presentes (aunque no contiguos, como sostenemos) de los participantes del acontecimiento. En cambio, el convivio, cuya definición radica en la adyacencia de los cuerpos en tiempo presente (aquí y ahora) sí es problemática frente al tecnovivio que no permitiría tal concurrencia.

Mientras que la definición filosófica del convivio considera la producción de un territorio diferenciado de la cotidianeidad y del que participan en cuerpo presente artistas, técnicos y espectadores, el teatro tecnovivial, mediado por las pantallas, no fundaría un espacio convivial por estar desterritorializado y, habiéndose sustraído el cuerpo, desmaterializaría la relación entre sus participantes (Dubatti, 2020). Esto supone que no se podría, en formato tecnovivial, instaurar un acontecimiento teatral y, lo que es más grave en términos políticos y éticos teniendo las condiciones tecnológicas que nos atraviesan como humanidad, sería imposible fundar una comunidad. Queda por dilucidar, por eso, si acaso el convivio sería una especie diferente y opuesta del tecnovivio o bien un aparato específico de producción de convivio, en otras palabras, si en el teatro tecnovivial ocurre la relación teatral o más bien estamos ante un fenómeno de teatro imposible cuya productividad radica, justamente, en la incapacidad de producir acontecimiento teatral.

La articulación entre poiesis y expectación en un mismo espacio y tiempo garantiza, en definitiva, la existencia ontológica del teatro. Ahora bien, ¿cuáles son las condiciones para que este supuesto se cumpla? ¿Existe una única forma de reunión que las pantallas e internet nos alienan? ¿Cómo se mide la distancia/mismidad entre los espacios y tiempos de espectadores y artistas? De acuerdo con la Filosofía del teatro, el convivio es la forma en que la cultura viviente se manifiesta: “(...) el teatro exige la presencia viva, real, de cuerpo presente, de los artistas, en reunión con los técnicos y los espectadores" (Dubatti, J., 2015: 2). Siendo que el teatro ocurre en convivio, sin este encuentro la posibilidad del teatro-matriz desaparecería. Presente remite a un tiempo sincrónico, simultáneo, entre poiesis productiva y receptiva y, a la vez, la conciencia de lo irrepetible de esta sincronía.

Esta preocupación parece sostener la propuesta de Crónica de un hombre solo del grupo La Suripanta Banda Teatral. La Suripanta es un grupo formado en la ciudad de General Güemes, donde realizan además sus ensayos, formación de actores y talleres. A pesar de estar a $50 \mathrm{~km}$ de la ciudad de Salta, el aislamiento social impidió durante los meses más intensos de la cuarentena la movilidad de los artistas, quienes encuentran en la capital de Salta muchos de sus espectadores, sobre todo en lo que refiere a teatro experimental.

Junto con el anuncio del estreno de la obra, en el marco del Festival de Actores Independientes de Salta (FAISA), que en el año 2020 se realizó en formato virtual, se advertía a los posibles espectadores que se trataría de una única función. Junto con este valor, vinculado con la irrepetibilidad del acontecimiento, Germán Tolaba, autor y actor, señala lo siguiente en su perfil personal de Facebook: "Hoy única función. A vos, amigo, amiga, amigue que siempre andas preguntando cuando presento una obra. Esta es tu oportunidad para verme desde casa" (4/12/2020). La puesta en evidencia de la unicidad del hecho que va a ocurrir, Tolaba destaca la poiesis receptiva desde casa como una oportunidad. Esto debe entenderse en el marco de la práctica artística de un grupo que, desde el interior de la provincia, se encuentra permanentemente con dificultades de transporte, acceso a salas y encuentro con el público. 
La puesta en escena se realizó en la Sala a Mitad de Pasillo en Salta capital y, desde allí, se transmitió en vivo a través de la plataforma Pass Line. Tolaba destacó en diversas entrevistas personales la posibilidad que tuvo, con esta puesta, de ser visto por espectadores no solo de la provincia, consiguiendo así alcance internacional y propiciando un encuentro con espectadores conscientes de la finitud del hecho teatral y, en conjunto, construyendo una sala de espectadores rizomática, de características muy diferentes a la que propone el convivio tradicional. Con esto se observa que la diferencia entre convivio y tecnovivio no se da tanto en la posibilidad o no del encuentro como en el soporte y la forma particular de poner en relación espacios distantes.

Para la filosofía del teatro, un rasgo distintivo de la "encrucijada territorial y temporal" del convivio (Dubatti, J., 2020) es la ausencia de mediaciones técnicas entre productor y destinatario de la obra, ya que, para esta concepción, el teatro funda una territorialidad imposible con la intermediación tecnológica, ya que ésta sustraería los cuerpos del territorio y, en consecuencia, los desauratiza. Al respecto, cabe de hecho tener en cuenta en la reflexión observaciones que Rancière realiza al respecto de la producción de comunidad en teatro, rasgo que sería el que distinga el teatro convivial de formas no conviviales, como sería el tecnovivio:

El poder común de los espectadores no reside en su calidad de miembros de un cuerpo colectivo o en alguna forma específica de interactividad. Es el poder que tiene cada uno o cada una de traducir a su manera aquello que él o ella percibe, de ligarlo a la aventura intelectual singular que los vuelve semejantes a cualquier otro aun cuando esa aventura no se parece a ninguna otra (Rancière, J, 2010: 23)

Es decir que el poder de los espectadores reside más que en su semejanza o igualdad en su distancia y diferencia, en la capacidad de trazar un recorrido propio, intelectualmente emancipado. En este sentido, la reunión de los cuerpos del espectador en el teatro tecnovivial no es garantía ni de emancipación ni de comunidad. Más bien, la forma en que se produce la reunión. No existe relación de causalidad directa entre espectadores que se reúnen en un teatro para que exista la producción de la comunidad. Como no hay tampoco causalidad entre la distancia que plantea el teatro tecnovivial y la imposibilidad de producción de lo común. Podemos considerar que ambos son dos artefactos distintos que bien pueden convivir como aparatos posibles del dispositivo teatral. El teatro tecnovivial, sin embargo, aún debe asumir la prueba de la comunidad. Es preciso contrastar el solipsismo del tecnoespectador con la sumatoria de espectadores del teatro convivial sin asumir como un hecho la comunidad de uno u otro por la forma en que construye el contacto.

\section{Producción de territorios alternativos: hacia una mirada no- euclidiana sobre el espacio}

Según Dubatti, la experiencia tecnovivial está determinada por el formato tecnológico. El tecnovivio se define como "cultura viviente desterritorializada por intermediación tecnológica" (2015: 46). Al comentar el caso de Crónica de un hombre solo hemos señalado la posibilidad de que espectadores distantes participen de la experiencia teatral. El teatro tecnovivial abre nuevas posibilidades de considerar el espacio en el teatro y de producir territorios con esos espacios hab(il)itados. También es el caso de Troyanas, obra dirigida por Alejandro Orduna que se estrenó en formato convivial en el año 2017 en La Plata. Con la urgencia de repensar el teatro en pandemia, la propuesta fue trasladada al formato tecnovivial, permitiendo a espectadores de todo el país asistir al acontecimiento. 
Además de destacar este proceso territorial, semejante al que ocurre con los casos que venimos señalando, llama la atención y resulta pertinente pensar las diferencias entre los mecanismos entre la forma convivial y la tecnovivial para producir acontecimiento teatral. A modo de hipótesis, destaca de esta última obra mencionada el empleo de Telegram, Instagram y Zoom, en distintos momentos de la producción del acontecimiento teatral, con el objeto de convocar a los espectadores y adentrarnos en la poiésis, que se vuelve fractálica, multimedial y que, a nivel estético, encuentra su correlato en la forma de producción de las imágenes que, dicho sea de paso, solicitaban que el espectador no las comparta para mantener la integridad física de las artistas participantes.

Mientras que 5 pesos y Crónica de un hombre solo fueron proyectadas originalmente para ser experiencias tecnoviviales, Troyanas nos presenta la posibilidad de traducción entre convivio y tecnovivio. Ante esto, es preciso distinguir entre fenómenos de transteatralidad, en donde formas teatrales conviviales son digitalizadas, como sería el caso del teatro grabado y luego reproducido en redes, de experiencias propiamente teatrales, donde la tecnología es asumida como un factor que participa de la construcción de tecnovivio y la producción de una comunidad de espectadores. El tecnoespectador, como correlato específico de este artefacto que estamos delineando, y el teatro tecnovivial nos permiten tomar el pulso de la forma en que durante el 2020 se ha sostenido la producción de lo común y, tal vez, anticipar formas emergentes de comunidad que, en el futuro, tal vez sean las dominantes: "Conlleva una idea de la comunidad como presencia en sí, opuesta a la distancia de la representación" (Rancière, J. 2010: 13) o, en realidad, más allá de la representación y sus interpretaciones posibles.

Ahora bien, volviendo a la pregunta que nos interpela desde el inicio de este trabajo, la respuesta sobre si estas prácticas son o no teatro responde a las condiciones de producción del interrogante, es decir, la configuración del dispositivo. Si nos posicionamos en la tradición teórica con respecto al teatro existe un consenso en considerar teatro como la producción artística que, en el aquí y ahora simultáneos de espectadores, artistas y público, permite la emergencia de un tipo de acontecimiento que funda un territorio particular, una zona intersubjetiva e interactiva abierta a lo impredecible, efímera y abierta a la indeterminación. Definir el teatro por el convivio supone proponer una apreciación tautológica que no atiende a la complejidad de la producción de lo común y de la distancia como factor inherente de la comunidad.

Por otro lado, sostener que el teatro ha sido convivial desde sus orígenes implica, primero, un argumento que deshistoriza las prácticas teatrales y, segundo, estudiar teatro rara vez implica estudiar el hecho en sí, sino más bien sus repercusiones, su efecto aurático o su fuerza performativa. La repetición de una puesta en escena es la instancia fundamental para la producción de un aura, la cual que no se refiere a un hecho particular, sino al conjunto de vectores que la van configurando. Por usar una imagen, nunca vemos la piedra que cae al agua, lo que vemos son sus ondas y, esas ondas, nos permiten llegar a la piedra, al menos como hipótesis de trabajo que rara vez, mientras más lejano en el tiempo y en el espacio se ubique, se podrá constatar.

Por supuesto que no estamos refiriéndonos a una homología que disuelva la diferencia entre convivio y tecnovivio como aparatos y su relación con el dispositivo teatral. $\mathrm{Al}$ respecto de esto, Diego López considera esta forma de hacer teatro como una variante teatral entre otras, que genera sus propias discusiones y que surge como una alternativa de resistencia del teatro en el contexto de pandemia. Señala algunas características pertinentes para esta discusión a propósito de 5 pesos:

Obra creada a través de entornos virtuales para ser vista también a partir de la plataforma Zoom. Creemos que esta nueva forma de hacer teatro no reemplaza 


\begin{abstract}
ni quiere sacar al teatro con la persona y la presencialidad, sino una variante más que esta pandemia posibilitó. Encontramos en la virtualidad un aliado para seguir haciendo teatro. (...) Fue una instancia de mucho debate hasta que decidimos que la obra se hacía por Zoom y se hacía por vivo (...) que tenga la misma sensación que cuando uno va al teatro (Entrevista a Diego López, 25-12-2020)
\end{abstract}

Hemos señalado que hay diferentes modos de usar el instrumento tecnológico para producir distintos tipos de artefactos, en este sentido no es lo mismo una clase sincrónica que una asincrónica y la diferencia no está en si usan o no la pantalla, sino en cómo la pantalla interviene y en los supuestos pragmáticos de sintopía y sincronía. Oponer los conceptos de tecnovivio y convivio sirven para marcar las diferencias entre formas de lo artístico. Sin embargo, esto no debería suponer que el convivio no es una tecnología que articula la relación entre los cuerpos. Suponiendo una homología entre el aquí y ahora del actor y del espectador fundado en la contigüidad espacial de los cuerpos en el acontecimiento como rasgo inherente del teatro obtura la consideración de que el aquíy ahora del actor, del técnico y del espectador es más el resultado de una convención consolidada a lo largo de los siglos y reafirmada con la aparición de aparatos de reproducción técnica de imágenes en movimiento que una característica inherente de los aparatos de reproducción técnica y la intermediación tecnológica la producción de comunidad humana.

Como podemos observar, tecnovivio y convivio son formas diversa de organizar lo público y de posicionarse frente a otras formas de organización y otras tecnologías, en otras palabras, "Cada tecnología determina cambios en las condiciones del vivir juntos." (Dubatti, J., 2015: 47). Esto no niega que en las diferentes condiciones de vivir juntos no haya tecnología, que alguna sea natural, ancestral o apolítico. Dubatti plantea una no competencia entre paradigmas: "En realidad, no hay competencia: se trata de dos paradigmas diversos de la existencia. Cada paradigma implica una política (vital, e incluso de defensa, apología o rechazo) muy diferente" (2015: 47). $\mathrm{Al}$ contrario de esta postura ecuménica, afirmamos la competencia entre estos dos aparatos en el marco del dispositivo teatral, en tanto cada uno tiene un valor y una posición en el campo que, actualmente, se encuentra en pugna.

No son los instrumentos tecnológicos los que sustraen el cuerpo y permiten distinguir como teatral a un artefacto semiótico, sino la forma peculiar de producir la relación entre los cuerpos. Es preciso cambiar el foco del medio y llevarlo al modo y los materiales, dimensionar la pragmática y performática de la relación y revisar qué clase de encrucijada territorial y temporal se produce, cómo se organizan los roles y diferencias entre artistas, técnicos y espectadores. La diferencia no es de modo, sino de materiales. Desde una perspectiva de proceso territorial, el trabajo con el espacio - en sentido inespecífico- implica el reconocimiento de las particularidades, es decir, las determinaciones y posibilidades que cada espacio propone o impone. El teatro a la italiana organiza la relación espacial de una forma diferente a la que puede hacerlo una procesión o un escenario circular. Lo común en todas las prácticas teatrales es su carácter temporalmente sincrónico y territorialmente sintópico, donde la diferencia temporal y espacial entre técnicos, espectadores y actores se disuelve a favor de la producción de un territorio convencional, que no cotidiano, que redistribuye los roles y las funciones en relación con la ubicación en el espacio y la prescripción de acciones en relación con los elementos de la praxis semiótica.

La contigüidad espacial es una característica del convivio teatral, sin embargo, considerar que solo se produce el acontecimiento teatral en contigüidad impide considerar la producción de contacto y comunidad y la teatralidad de prácticas contemporáneas. Además del peligro de invisibilizar obras realizadas en el campo teatral, también oculta formaciones territoriales cuya configuración espacial se funda en la distancia: eventos, como el FAISA, el Encuentro Internacional de Mimo y Clown Salta, que en 
2020 se realizó en formato digital, la Fiesta Regional del Teatro 2020, entre otros y obras como las que configuran el material de este trabajo así como metodologías que muestran la productividad de lecturas de la discontinuidad espacial (cfr. Tossi (2015)).

La positivización o negativización del tecnovivio tiene más que ver con políticas poéticas, simbólicas y económicas locales que con características propias de esta posibilidad de contacto. Así como en 2015 Dubatti señalaba "la necesidad de una política de valoración del convivio a través del teatro y de otras prácticas culturales y sociales" (2015: 50), a fines del 2020 y principios del 2021, la necesidad en las provincias es otra y es importante que sepamos diagnosticar esta diferencia. Esto es importante porque negar la posibilidad del teatro tecnovivial supone perder la posibilidad de inscribirse en legislaciones nacionales vigentes que tienen como objetivo desactivar la histórica desigualdad territorial al interior de nuestro país. Negar el teatro tecnovial supone inhabilitar el acceso a políticas públicas futuras de un centenar de artistas y espectadores que han sido históricamente marginados y que a pesar de ello - la pandemia global del 2020 lo ha demostrado - siguen sosteniendo el teatro en contextos de vulnerabilidad económica, cultural, territorial y, ahora, tecnológica. El teatro ha resistido al aislamiento social obligatorio y ha demostrado su capacidad de reinvención fundando y consolidando territorialidades disruptivas.

Negar la teatralidad o la inclusión del tecnovivio en el teatro implica que, sin ir más lejos, las prácticas tecnoviviales, cuyo costo de producción - en sentido social y no solo en sentido de grupos - es tanto o mayor que el teatro tradicional. Consideramos que el convivio definido como presencia simultánea en el mismo espacio de actores, espectadores y de técnicos es un tipo particular de tecnovivio, es decir, de tecnología del contacto de los cuerpos y códigos de interacción entre estos. Esto no implica que se diluya la distinción entre el tiempo y espacio producido por la tecnovivio que vincula los cuerpos en el cine, en el teatro o la literatura. Al contrario, permite pensar la diferencia en tanto tecnologías aplicadas a la producción social de la relación entre individualidades y la posibilidad de implicación y afectación de los cuerpos que se vinculan en espacialidades y temporalidades que se co-producen a propósito del artefacto.

Para la filosofía del teatro, en el teatro se produce una reunión territorial de cuerpo presente, lo que lo vincula con los asados, las fiestas de casamiento, los partidos de fútbol. Lo que se observa es que se considera como "territorio" a la adyacencia espacial de los partícipes en la poiesis. Lo cierto es que esta adyacencia material puede ser producida convencionalmente con la intermediación tecnológica, que a la vez define un umbral entre la experiencia de los distintos sujetos que participan de la poiesis. Hemos visto, sin embargo, que la desterritorialización no es inherente del teatro tecnovivial. Es el trabajo con espacios discontinuos para la producción de territorio y relación entre actores, técnicos y espectadores el rasgo definitorio del tecnovivio sincrónico.

Frente a perspectivas idealistas que parten de una definición a priori de lo que el teatro es y lo que deberíamos incluir en el concepto como parte de los proyectos de investigación, proponemos un posicionamiento materialista y fenomenológico que permita abrir los conceptos y, por lo tanto, su potencial analítico. Consideramos que no se trata solo de discutir categorías que nombran lo real, sino de entender que el acto de categorizar organiza el fenómeno e impacta sobre las prácticas y el reparto de los recursos sociales, culturales y económicos. Las posturas conservadoras le hacen el juego al neoliberalismo cultural que, desde una pretendida oposición a la subjetividad empresarial, termina consolidando a aquellos lugares, sujetos, instituciones que ya disponen de capitales económicos a punto de transformarse en capital simbólico.

El tecnovivo relativiza la necesidad de adyacencia del espectador, el actor y el técnico, sin que esto signifique asumir la imposibilidad del presente, del convivio o del 
territorio co-producido, llegando a postular la desterritorialización de las prácticas, la descorporeización del aparato semiótico y sus participantes o liminarizando su posición en el dispositivo teatral o social. Teatro sin teatro o teatro que se ha desbordado, que ha explotado su edificio y que ha conseguido reticularse, fluido, dinámico. Los escenarios se multiplican.

Dubatti niega el acontecimiento teatral cuando aparece la intromisión tecnológica: "Lo opuesto al convivio es el tecnovivio, es decir, la cultura viviente desterritorializada por intermediación tecnológica" $(2015,1)$. La supuesta desterritorialización del teatro virtual coloca la territorialidad y la espacialidad como elementos materiales constitutivos solo de la poiésis, que desconoce la diferencia espacial entre los cuerpos, niega la materialidad del cuerpo virtual y desdibuja los procesos de territorialización que sostienen la poiésis antes que el cuerpo poiético exista como tal o cuando este ya no existe sino dentro de la memoria, es decir, en sus momentos productivos y repercutivos (Crf. Kent en prensa, 2019).

Actualmente, es imposible la sustracción - aunque sí ficcional, convencional, por pacto de expectación - de los cuerpos en el tecnovivo. La posibilidad del emergente y de hacernos cargo de su ocurrencia, característica propiamente teatral, ocurre empleando pantallas, la tecnología de la pantalla sirve para implicarnos en la temporalidad de la historia, como son los muchos recursos que se puede rastrear en las obras del corpus. En un intento de mantener al teatro a salvo de la amenaza de internet es que se desconoce la teatralidad de múltiples prácticas posibles en internet y el potencial que internet y las pantallas tienen en la producción de hechos conviviales.

\section{Cierre provisorio}

Tecnovivio y convivio son semejantes en su capacidad de producción de experiencia compartida, ambas se fundan en una misma temporalidad, que es la sincronía, y en una forma de espacialidad, la sintopía. La diferencia radica en que el convivio se funda en una experiencia de continuidad espacial, mientras que el tecnovivio habilita la producción territorial a partir de espacios discontinuos. No se diferencian por ser dispositivos técnicos, en tanto ambos lo son, sino en la forma de la técnica, que no es un problema ajeno al convivio (teatro a la italiana). Tampoco en la desterritorialización y descorporeización, en tanto el tecnovivio es tan corporal y territorial como el convivio, en tanto en ninguna de las producciones examinadas fue posible sustraer el cuerpo actuando o espectando. Son justamente las similitudes en cuanto a criterios los que nos permite compararlos en tanto formaciones diferentes.

El tecnovivio es capaz de producir y consolidar territorios teatrales con una eficacia inusitada. Es el caso del mencionado, Festival de Actores Independientes de Salta (FAISA) que ha conseguido llevar el teatro local a formatos audiovisuales, ofreciendo un evento que no sólo ha incluido prácticas teatrales tecnoviviales, sino también audiovisuales, teatro grabado, recitales, espectáculos de magia. Sin dudas, este festival fue una oportunidad para que agentes del campo teatral local pudieran dar a conocer producciones realizadas durante la pandemia durante 2020. Pudimos observar los modos en que el recurso de la mediación tecnológica, la mirada a través de la cámara y las posibilidades de un ojo que sigue al actor abren a la producción de espectáculos. Además, ha sido la oportunidad de explorar modos de traducción de convivio a tecnovivio, demostrando la capacidad artística plena de la segunda para producir una experiencia tecnovivial. Lo interesante de estas producciones ha sido que el teatro llega a los hogares. Los efectos de este trabajo de creación es el incremento considerable del acervo de recursos de los que dispone el teatro tecnovivial y la apertura de líneas de indagación en relación con la producción de territorios y comunidades de espacios discontinuos. 


\section{Dibliografía}

» Bourdieu, P. (2010). El sentido social del gusto. Elementos para una sociología de la cultura. Buenos Aires: Siglo Veintiuno Editores

"Dubatti, J. (2010). Filosofía del teatro Il: cuerpo poético y función ontológica. Buenos Aires: Atuel

"Dubatti, J. (2012). "El teatro de los muertos: teatro perdido, duelo, memoria del teatro. Problemas epistemológicos" en Filosofía del teatro III. Buenos Aires: Atuel

"Dubatti, J. (2015). "Convivio y tecnovivio: el teatro entre infancia y babelismo" Revista Colombiana de las Artes Escénicas, 9, 44-54.

»Dubatti, J. (2020). Teatro y territorialidad. Perspectivas de Filosofía del Teatro y Teatro Comparado. Barcelona: Gedisa

»Eco, H. (1965) Obra abierta. Barcelona: Editorial Seix Barral

"Haesbaert, R. (2011). El mito de la desterritorialización: del "fin de los territorios" a la multiterritorialidad. México: Siglo XXI

"Entrevista a Diego López por Escena Activa: https://www.youtube.com/ watch?v=O8jH6qxVaos

»Kent Trejo, D. [en prensa] “La experiencia teatral: apuntes para un 'respectador"”

»Kent Trejo, D. (2019). “El respectador ante la liminalidad de la experiencia teatral” en Dubatti, J. (coord.) Poéticas de liminalidad en el teatro II. Lima: Escuela Nacional Superior de Arte Dramático

»Rancière, J. (2000). El reparto de lo sensible. Santiago de Chile: LOM Ediciones

» Tossi, M. (2015). "Los estudios del teatro regional en la posdictadura argentina: desafíos teóricos e implicancias políticas” en Mitologías hoy. Revista de pensamiento, crítica y estudios latinoamericanos Vol. 11. Disponible en https://revistes. uab.cat/mitologias/article/view/v11-tossi 